\title{
Secreted Interferon-Inducible Factors Restrict Hepatitis B and C Virus Entry In Vitro
}

\author{
Yuchen Xia, ${ }^{1}$ Xiaoming Cheng, ${ }^{1}$ Christoph K. Blossey, ${ }^{1}$ Karin Wisskirchen, ${ }^{1,2}$ \\ Knud Esser, ${ }^{1}$ and Ulrike Protzer ${ }^{1,2}$ \\ ${ }^{1}$ Institute of Virology, Technische Universität München/Helmholtz Zentrum München, 81675 Munich, Germany \\ ${ }^{2}$ German Center for Infection Research (DZIF), Partner Site Munich, Munich, Germany \\ Correspondence should be addressed to Yuchen Xia; yuchen.xia@nih.gov
}

Received 14 September 2016; Revised 24 January 2017; Accepted 6 February 2017; Published 6 March 2017

Academic Editor: Ghislain Opdenakker

Copyright (C) 2017 Yuchen Xia et al. This is an open access article distributed under the Creative Commons Attribution License, which permits unrestricted use, distribution, and reproduction in any medium, provided the original work is properly cited.

Interferon- $\alpha($ IFN- $\alpha)$ has been used for more than 20 years as the first-line therapy for hepatitis B virus (HBV) and hepatitis C virus (HCV) infection, because it has a number of antiviral effects. In this study, we describe a novel mode of its antiviral action. We demonstrate that the supernatant from IFN- $\alpha$-treated cultured cells restricted HBV and HCV infection by inhibiting viral entry into hepatoma cells. The factors contained in the supernatant competed with the virus for binding to heparan glycosaminoglycansthe nonspecific attachment step shared by HBV and HCV. Secreted factors of high molecular mass that bind to heparin columns elicited the antiviral effect. In conclusion, IFN- $\alpha$ is able to induce soluble factors that can bind to heparan glycosaminoglycans thus leading to the inhibition of viral binding.

\section{Introduction}

Interferon (IFN) was first discovered in 1957, based on the observation that cells challenged with heat-inactivated influenza virus secreted a macromolecule that was able to "interfere" with several viruses, such as the infectious influenza virus or vaccinia virus [1]. This study and followup researches led to the development of IFN as a therapeutic tool to treat a number of infectious diseases, in particular chronic hepatitis B and hepatitis C. IFN elicits antiviral actions by inducing a wide array of IFN-stimulated genes (ISGs). By interacting with their specific receptors, IFN activates signal transducer and activator of transcription (STAT) complexes. Phosphorylated STAT then activates the classical Janus kinase-STAT signaling pathway and initiates the transcription of different ISGs [2].

The mechanisms by which these ISGs participate in the IFN-mediated response to hepatitis B virus (HBV) or hepatitis $\mathrm{C}$ virus (HCV) are not fully understood. Previous studies demonstrated that IFN inhibits HBV replication at multiple steps of its life cycle, by deaminating and degrading the viral transcription template covalently closed circular DNA (cccDNA) through apolipoprotein B mRNA editing enzyme catalytic subunit 3A [3-5], silencing cccDNA through epigenetic regulation by the STAT complex $[6$, 7], downregulating viral mRNA stability through antiviral zinc finger proteins $[8,9]$, inhibiting viral pregenomic RNA encapsidation via myxoma resistance protein $1[10,11]$, and reducing virion secretion by Tetherin [12]. IFN also promotes viral nucleocapsid degradation [13].

$\mathrm{HCV}$ and host ISGs show a much more complex interaction. For example, cellular pattern recognition receptors detect molecular patterns of HCV [14, 15], thereby forming a positive feedback loop to amplify IFN signaling. Many ISGs are reported to inhibit HCV RNA replication or viral protein translation, either directly or indirectly, including RNA-specific adenosine deaminase [16], viperin [17], and $2^{\prime}-5^{\prime}$-oligoadenylate synthetase [18]. IFN also induces transmembrane protein 1 (IFITM1) which was reported to inhibit HCV entry [19].

Virus entry can be a multistep process, in which the virus first attaches to cell type unspecific molecules, then binds to its specific receptor, and enters the cell. Heparan sulfate is present on the surface and in the extracellular matrix of 
all mammalian cells and serves as an attachment factor or anchor for a number of enveloped viruses such as herpes simplex virus [20], respiratory syncytial virus [21], human immunodeficiency virus [22], cytomegalovirus [23], Dengue virus [24], HBV [25], and HCV [26], as well as nonenveloped viruses such as human papillomavirus [27] and foot-andmouth disease virus [28].

Although the influence of ISG products on the replication of HBV or HCV has been studied extensively, little is known about the influence of IFN treatment on early steps of the virus life cycle. Here, we investigated whether IFN- $\alpha$ was able to induce soluble factors that would have extracellular antiviral activity. Our study reveals a novel antiviral mechanism of IFN- $\alpha$. Upon IFN- $\alpha$ treatment factors are secreted that bind to heparan glycosaminoglycans - the attachment receptor of many viruses including $\mathrm{HBV}$ and $\mathrm{HCV}$-thus leading to the inhibition of virus attachment and blocking infection.

\section{Materials and Methods}

2.1. Cell Cultures. HepaRG cells were cultured in Williams E medium (Gibco, Carlsbad, USA) supplemented with 10\% fetal calf serum FetalClone II (HyClone, Little Chalfont, United Kingdom), 20 mM L-glutamine (Gibco, Carlsbad, USA), $50 \mathrm{U} / \mathrm{mL}$ penicillin/streptomycin (Gibco, Carlsbad, USA), $80 \mu \mathrm{g} / \mathrm{mL}$ gentamicin (Ratiopharm, Ulm, Germany), $0.023 \mathrm{IE} / \mathrm{mL}$ human insulin (Sanofi-Aventis, Paris, France), and $4.7 \mu \mathrm{g} / \mathrm{mL}$ hydrocortisone (Pfizer, Carlisle, USA) as described [29]. The cell cultures were maintained in a 5\% CO2 atmosphere at $37^{\circ} \mathrm{C}$. For infection, cells were maintained for 2 weeks in standard medium and then differentiated for 2 more weeks in medium supplemented with 1.8\% DMSO (Sigma, Munich, Germany).

2.2. HBV Production. HBV was concentrated from the supernatant of HepG2.2.15 cells using centrifugal filter devices (Centricon Plus-70, Biomax 100.000, Millipore Corp., Bedford, MA) and quantified by HBV-DNA qPCR. Immediately after collection, the virus stock was divided into aliquots and stored at $-80^{\circ} \mathrm{C}$ until use.

2.3. HBV Infection. The inoculation of differentiated HepaRG cells was performed with a multiplicity of infection of 200 (genome copies per cell) in differentiation medium containing 5\% PEG 8000 (Sigma, Munich, Germany) for $16 \mathrm{~h}$ at $37^{\circ} \mathrm{C}$. At the end of the incubation period, cells were washed three times with PBS and cultured in differentiation medium.

2.4. Analysis of $H B V$ Replication. HBsAg was measured using the AXSYM system (Abbott, Chicago, USA), and HBeAg was measured by the BEP III system (Siemens, Munich, Germany). Total cellular DNA or DNA from cell culture supernatant were extracted from infected cells using NucleoSpin Tissue Kit (Macherey-Nagel, Düren, Germany). Real-time quantitative PCRs (qPCRs) were performed using the LightCycler ${ }^{\mathrm{TM}}$ system (Roche, Manheim, Germany) and HBV-DNA and cccDNA were detected using specific PCR
TABLE 1: Primers for qPCR.

\begin{tabular}{|c|c|}
\hline Name & Sequence $5^{\prime}-3^{\prime}$ \\
\hline cccDNA $92 \mathrm{fw}$ & GCCTATTGATTGGAAAGTATGT \\
\hline cccDNA $2251 \mathrm{rev}$ & AGCTGAGGCGGTATCTA \\
\hline PRNP fw & GACCAATTTATGCCTACAGC \\
\hline PRNP rev & TTTATGCCTACAGCCTCCTA \\
\hline rcDNA1745 fw & GGAGGGATACATAGAGGTTCCTTGA \\
\hline rcDNA1844 rev & GTTGCCCGTTTGTCCTCTAATTC \\
\hline
\end{tabular}

primers (Table 1). HBV-DNA from cell culture supernatant was quantified relative to an external plasmid standard. Intracellular HBV-DNA and cccDNA are expressed as normalized ratio to the genomic single copy gene of the prion protein (PRNP).

2.5. Western Blot. Lysates from HepaRG cells were obtained by adding $200 \mu \mathrm{L}$ "M-PER Mammalian Protein Extraction Reagent" (Thermo Scientific, Schwerte, Germany) onto cells per well and incubated at $37^{\circ} \mathrm{C}$ for five minutes. $50 \mu \mathrm{L}$ "LDS sample buffer Nonreducing" was added and samples were shaken for five minutes at $800 \mathrm{rpm}, 99^{\circ} \mathrm{C}$. Proteins were separated on $7.5 \%$ sodium dodecyl sulfate-polyacrylamide gel electrophoresis. Then, proteins were blotted onto a PVDF membrane. The membrane was blocked with $5 \%$ milk for one hour at room temperature followed by overnight incubation with polyclonal rabbit anti-HBV core antibody (gift from Heinz Schaller) at $4^{\circ} \mathrm{C}$.

2.6. Virus Heparin Attachment Assay. 96-well plates were coated with $100 \mu \mathrm{L}$ of a $25 \mu \mathrm{g} / \mathrm{mL}$ heparin solution per well and incubated at $4^{\circ} \mathrm{C}$ overnight. The wells were washed 3 times with PBS. Then $100 \mu \mathrm{L}$ of samples was added and the plate was incubated overnight at $4^{\circ} \mathrm{C}$. The samples were aspirated and the plate was washed 3 times with PBS. $300 \mu \mathrm{L}$ of blocking buffer (1\% BSA solution in PBS-T) was added to each well and incubated for $2 \mathrm{~h}$ at $37^{\circ} \mathrm{C}$. After that, the plate was washed 3 times with PBS-T.

$100 \mu \mathrm{L}$ of blocking buffer, $1 \mu \mathrm{L}$ of virus stock solution, and $50 \mu \mathrm{L}$ Murex Conjugate solution (from Murex HBsAg Version 3 Kit, Saluggia, Italy) were added per well. The plate was incubated at $37^{\circ} \mathrm{C}$ for $1 \mathrm{~h}$ followed by 4 times with PBS$\mathrm{T}$ washing. Then, $100 \mu \mathrm{L}$ of substrate solution was added per well. After $1 \mathrm{~h}$ incubation at $37^{\circ} \mathrm{C}, 50 \mu \mathrm{L}$ stop solution $(1 \mathrm{M}$ $\mathrm{H}_{2} \mathrm{SO}_{4}$ in ddH2O) was added per well. Light absorption was measured at $450 \mathrm{~nm}$, with $670 \mathrm{~nm}$ reference wavelengths with an Infinite 200 (Tecan, Männedorf, Switzerland).

2.7. Enzymes Treatment Assay. Samples were treated with $50 \mathrm{U} / \mathrm{mL}$ N-glycosidase F beads (EDM Millipore, Bedford, MA) overnight at $37^{\circ} \mathrm{C}$, or $0.0005 \%$ Trypsin (Gibco, Carlsbad, USA) for 1 hour at $37^{\circ} \mathrm{C}$, or $0.1 \mu \mathrm{g} / \mathrm{mL}$ proteinase $\mathrm{K}$ for 1 hour at $37^{\circ} \mathrm{C}$. After incubation, $5 \mathrm{mM}$ protease inhibitor Pefabloc (Sigma, Munich, Germany) was added to the samples. Finally, the samples were purified with Vivaspin MWCO 3000 SpinColumn (Gelifesciences, Freiburg, Germany). 
2.8. Preparation of Luciferase Reporter HCV Stocks. Huh7.5 cells were electroporated with reporter constructs pFK-Luc$\mathrm{Jcl}$ as described previously [30]. Culture supernatant of transfected cells was harvested and filtered through $0.45 \mu \mathrm{m}$ Stericup ${ }^{\circledR}$ Filter Units (SCHVU11RE, Millipore, Germany) and precipitated with $8 \%$ PEG 8000 at $4^{\circ} \mathrm{C}$ overnight. Virus was pelleted by centrifugation at $5000 \times \mathrm{g}$ for $2.5 \mathrm{~h}$ at $4^{\circ} \mathrm{C}$, resuspended in DMEM, and stored at $-80^{\circ} \mathrm{C}$ before use. Each preparation was titrated for its infectivity by limiting dilution assay on Huh7.5 cells and 50\% and the tissue culture infective dose $\left(\mathrm{TCID}_{50}\right)$ was calculated based on the method described [31].

2.9. HCV Infection and Luciferase Assay. Huh7.5 cells were seeded in a 96-well plate $\left(1 \times 10^{4} /\right.$ well $)$ for $24 \mathrm{~h}$ prior to $\mathrm{HCV}$ inoculation. 0.1 MOI/cell of HCV luciferase virus were used to infect the cells for $72 \mathrm{~h}$. $10 \mu \mathrm{L}$ of prepared "elution" and "concentrate" was present in the $200 \mu \mathrm{L}$ culture medium during the whole process of HCV infection. Luciferase assays were performed using the assay kit (E1500, Promega, USA) following manufacturer's instructions. Luminescence was measured in programmed inject-then-read mode (Infinite F200, Männedorf, Switzerland). All luciferase assays were performed in triplicate.

2.10. Statistical Analysis. Student's unpaired two-tailed $t$ tests were performed with GraphPad Prism 5.0a (GraphPad Software, La Jolla, CA, USA). Data are means \pm s.d. Twosided $P$ values $<0.05$ were considered significant. ${ }^{*} P<0.05$, ${ }^{* *} P<0.01$, and ${ }^{* * *} P<0.001$.

\section{Results}

3.1. Pretreatment with IFN- $\alpha$ Inhibits HBV Replication. We first sought to investigate whether pretreatment of HepaRG cells with IFN-a before infection with HBV would have an effect on establishment of HBV infection (Figure 1(a)). IFN- $\alpha$ pretreatment resulted in a decline of $\mathrm{HBeAg}$ and HBsAg at day 10 upon HBV infection (Figures 1(b) and 1(c)). Concomitantly, intracellular HBV replication markers at day 10 were analyzed, and qPCR analysis revealed more than $50 \%$ reduction of cccDNA and intracellular HBV-DNA after IFN$\alpha$ pretreatment (Figure $1(\mathrm{~d})$ ). Western blot analysis showed the decline of intracellular HBV core protein production (Figure 1(e)). These results suggested that the pretreatment of cells with IFN- $\alpha$ for 24 hours is sufficient to induce an antiviral effect and the IFN-induced antiviral factors sustained this activity during infection. These results also implied that IFN- $\alpha$ induces an antiviral program preventing HBV early infection.

\subsection{Interferon-Inducible Secreted Factors Restrict Early Steps} of $H B V$ Infection. In order to determine whether the IFN$\alpha$ induced antiviral program would prevent initiation of HBV replication or inhibit attachment or entry into the host cell a conditioned medium was prepared from IFN- $\alpha$ treated cells (Figure 2(a)). The medium containing the ISG products (ISG+) was collected and added together with HBV to differentiated HepaRG cells. Compared with untreated cells, ISG+ medium treated cells showed decreased cccDNA and intracellular HBV-DNA demonstrating the inhibitory effect of ISG+ medium (Figure 2(b)). The ISG+ medium did not have an effect when it was applied to cells that had already been infected (Figure 2(c)).

To exclude that the antiviral action elicited by ISG+ medium was due to residual IFN- $\alpha$, neutralizing antibodies (IFN- $\alpha-\mathrm{Ab}$ ) were applied. When either IFN- $\alpha$ or ISG+ medium was added concomitantly with the HBV inoculum, HBV infection was inhibited, but only the effect of IFN- $\alpha$ but not that of ISG+ medium was neutralized by IFN- $\alpha \mathrm{Ab}$ (Figure 2(d)). This proved that the antiviral activity of ISG+ medium was not elicited by residual IFN- $\alpha$.

Taken together, the experiments show that ISG+ medium decreased HBV infection in cells treated before or during HBV infection, whereas no effect was observed if cells were treated following HBV infection. Thus we concluded that IFN- $\alpha$ treatment induces hepatoma cells to secrete soluble factors, and those soluble factors inhibit HBV infection by targeting an early step of HBV infection, most likely virus entry.

3.3. Interferon Induced Factors Interrupt HBV Binding. To further characterize the effect of interferon induced factors, we performed a virus attachment assay (Figure 3(a)). Differentiated HepaRG cells were incubated with mock (untreated differentiated HepaRG cell culture supernatant), ISG+ medium, heat-inactivated ISG+ medium (ISG+ inactivated), or the synthetic antilipopolysaccharide peptide Pep192.5 , which served as a positive control as it has been shown to inhibit the binding step of many enveloped viruses including HBV [32]. Cells were then inoculated with virus particles for 4 hours at $4^{\circ} \mathrm{C}$, because low temperature prohibits HBV entry into the host cell. Hereby, we found that interferon induced soluble factors could inhibit HBV binding as efficiently as Pep19-2.5, and heat inactivation led to attenuation of the antiviral effect (Figure 3(b)).

These results demonstrate that HBV binding to its host cell was impeded by treatment with ISG+ medium containing interferon induced soluble factors. We therefore speculated that the induced antiviral proteins associated with the virus itself or with one of the essential viral attachment factors or receptors.

\subsection{Interferon Induced Factors Interrupt HBV Binding to} Heparin Sulfate. Experimental evidence has been presented that HBV initiates infection of hepatocytes by binding to heparan sulfate proteoglycans [25]. We therefore analyzed whether IFN- $\alpha$ induced factors can interrupt the interaction between HBV and heparin, which is a close homologue of liver heparin sulfate [33]. We applied cell culture supernatant of untreated, differentiated HepaRG cells, ISG+ medium, or Pep19-2.5 on heparin columns and analyzed the residual binding capacity of HBV (Figure 4(a)). HBV virions efficiently bound to heparin-Sepharose under physiological salt conditions (mock) and could be eluted using high salt concentration (Figure 4(b)). HBV particle binding to heparin 


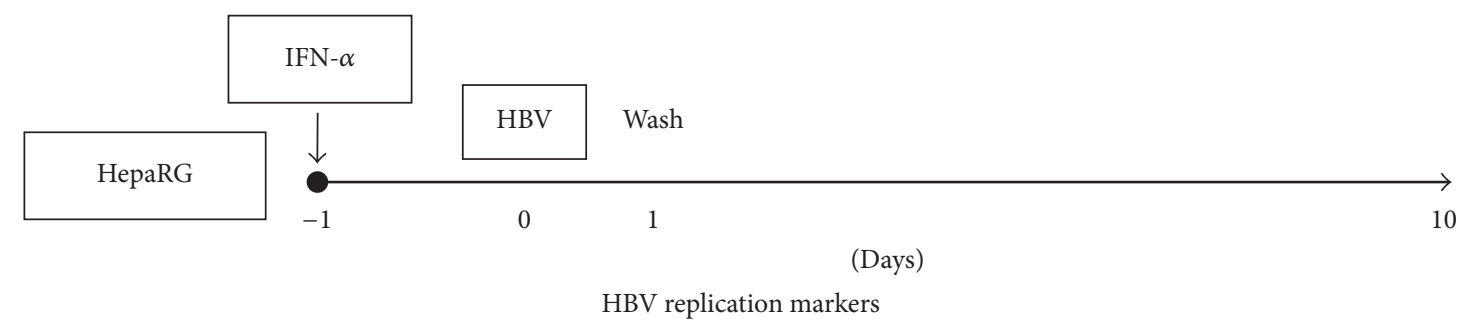

(a)



(b)



(c)

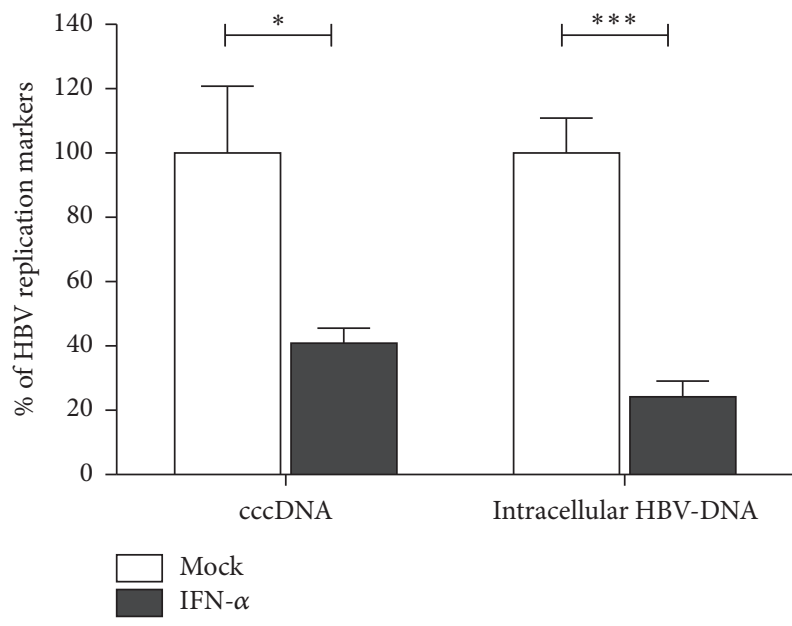

(d)

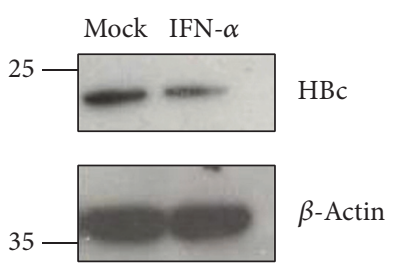

(e)

FIGURE 1: IFN- $\alpha$ pretreatment inhibits HBV infection. Differentiated HepaRG cells were treated with 1000 IU/mL of IFN- $\alpha$ for 1 day (IFN$\mathrm{a}(-1))$ and then infected with HBV (MOI = 200) (a). HBeAg from cell culture supernatant was measured by ELISA at day 10 (b). HBsAg was measured at day 7 and day 10 (c). HBV cccDNA and intracellular DNA were evaluated by qPCR (d). HBV core was detected by Western blot (e). Data are means \pm s.d. ${ }^{*} P<0.05,{ }^{* *} P<0.01$, and ${ }^{* * *} P<0.001$ by Student's unpaired two-tailed $t$-test.

was reduced by $30 \%$ when particles were loaded after ISG+ medium. Hereby ISG+ medium inhibited HBV binding to heparin column almost as efficiently as Pep19-2.5 that has been described previously [32]. These results demonstrate that ISG+ medium competes with HBV for binding to heparin.

To further investigate our hypothesis that soluble factors in the ISG+ medium competitively bind to heparin in cultured cells, ISG+ medium was applied to the heparin column, and the flow-through (low heparin affinity part) and the elution (high heparin affinity part) were collected and applied to differentiated HepaRG cells (Figure 5(a)). The elution fraction from the heparin column containing high heparin affinity factors led to a reduction of HBV binding to HepaRG cells while the flow-through fraction showed no significant inhibition (Figure 5(b)). In conclusion, these results show that interferon induced factors inhibit initial binding of HBV to the cell surface by direct interaction with heparan sulfate. 


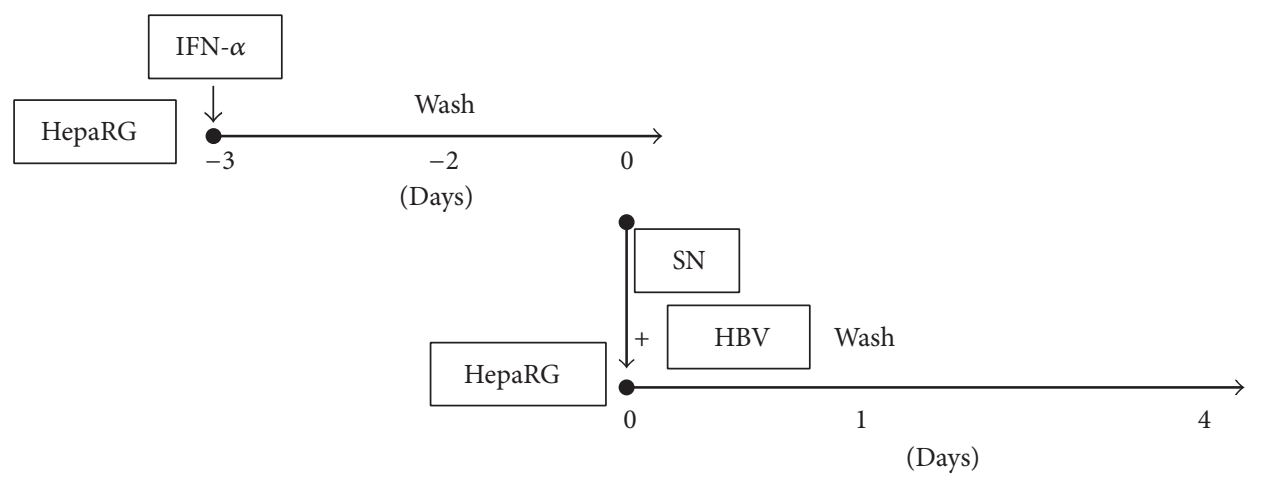

HBV replication markers

(a)
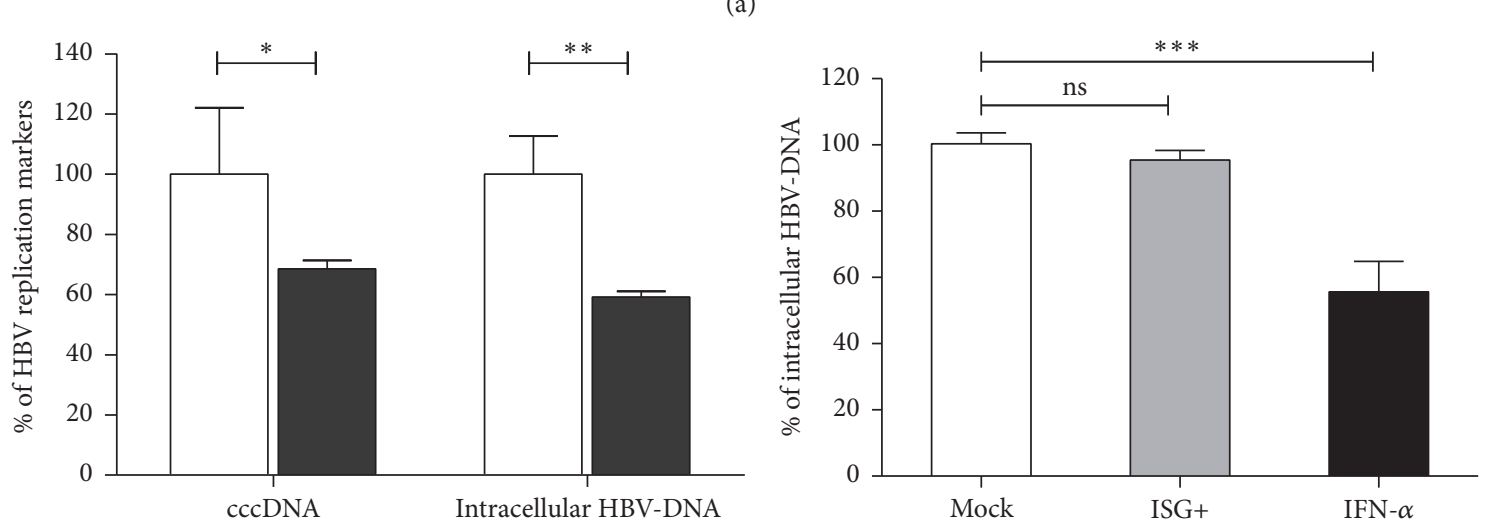

Mock

ISG+

(b)

(c)

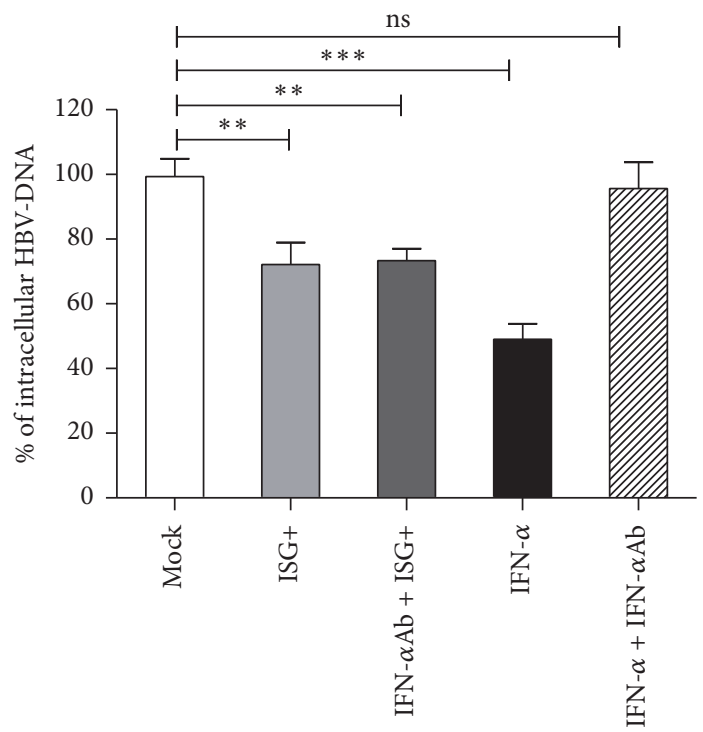

(d)

FIGURE 2: Secreted ISGs restrict early steps of HBV infection. (a) Differentiated HepaRG cells were treated with $1000 \mathrm{IU} / \mathrm{mL}$ of IFN- $\alpha$. One day later, the medium was removed. Cells were washed three times with PBS and refilled with new medium. The resulting medium containing interferon induced factors (ISG+) was collected 48 hours later and then mixed with HBV and PEG. The mixture then transferred onto fresh differentiated HepaRG cell for HBV infection. (b) HBV cccDNA and intracellular DNA were evaluated by qPCR 4 days after infection. (c) Differentiated HepaRG cells were infected with HBV $(\mathrm{MOI}=200)$ and 7 days later different treatments were applied as indicated. Intracellular HBV-DNA was measured 4 days after treatment. (d) Differentiated HepaRG cells were incubated with indicated treatment for 24 hours and then infected with HBV $(\mathrm{MOI}=200)$. Intracellular HBV-DNA was measured 4 days after infection. Data are means \pm s.d. ${ }^{*} P<0.05$, ${ }^{* *} P<0.01$, and ${ }^{* * *} P<0.001$ by Student's unpaired two-tailed $t$-test. 


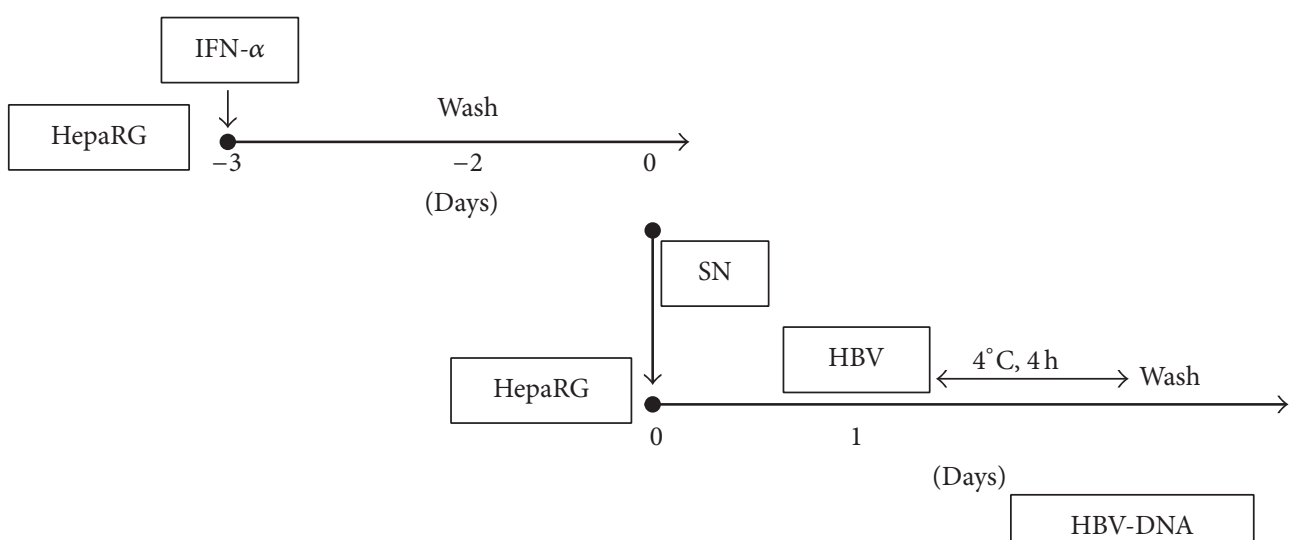

(a)

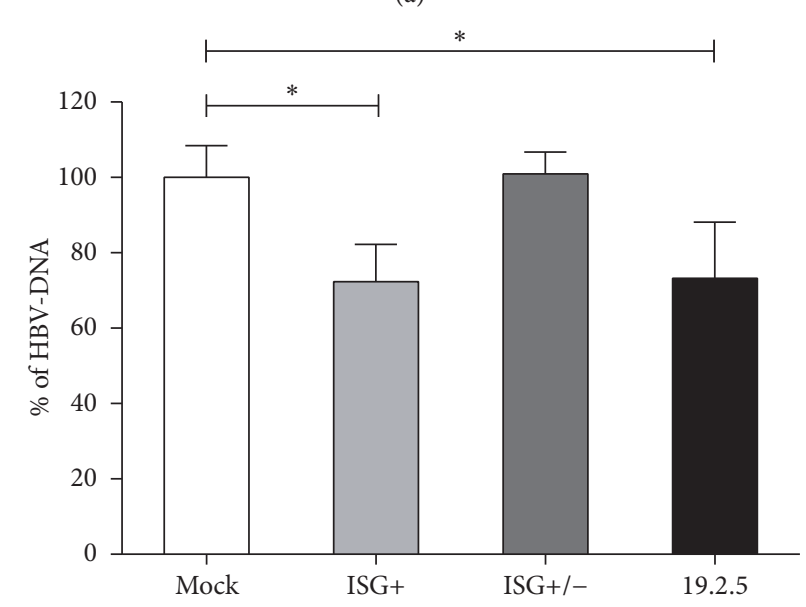

(b)

FIGURE 3: Secreted ISGs interrupt HBV binding. (a) Differentiated HepaRG cells were treated with $1000 \mathrm{IU} / \mathrm{mL}$ of IFN- $\alpha$. One day later, the medium was removed. Cells were washed three times with PBS and refilled with new medium. The resulting medium containing interferon induced factors (ISG+) was collected 48 hours later. Part of the medium was heated at $99^{\circ} \mathrm{C}$ for 10 minutes to inactivate proteins (ISG+/-). The medium was incubated with fresh differentiated HepaRG cells for 24 hours followed by 4 hours of $\mathrm{HBV}$ incubation at $4^{\circ} \mathrm{C}$. Peptide $19-2.5$ was used as a positive control. (b) Cells were lysed and HBV-DNA were evaluated by qPCR. Data are means \pm s.d. ${ }^{*} P<0.05$, ${ }^{* *} P<0.01$, and ${ }^{* * *} P<0.001$ by Student's unpaired two-tailed $t$-test.



(a)

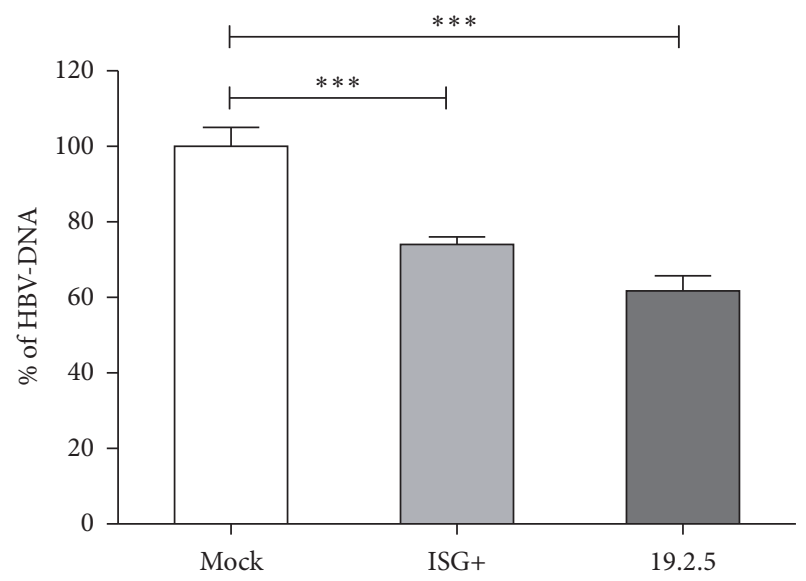

(b)

FIGURE 4: IFN- $\alpha$ induced products compete with HBV for binding to heparin column. (a) Heparin columns were washed with PBS and then applied with differentiated HepaRG cell culture medium (mock) or IFN- $\alpha$ treated differentiated HepaRG cell culture medium (ISG+) or the entry inhibitor Pep19-2.5. Then columns were applied with PBS containing HBV. After washing, HBV was eluted by elution buffer. (b) HBV amount from different elutions were analyzed by HBV-DNA qPCR. 


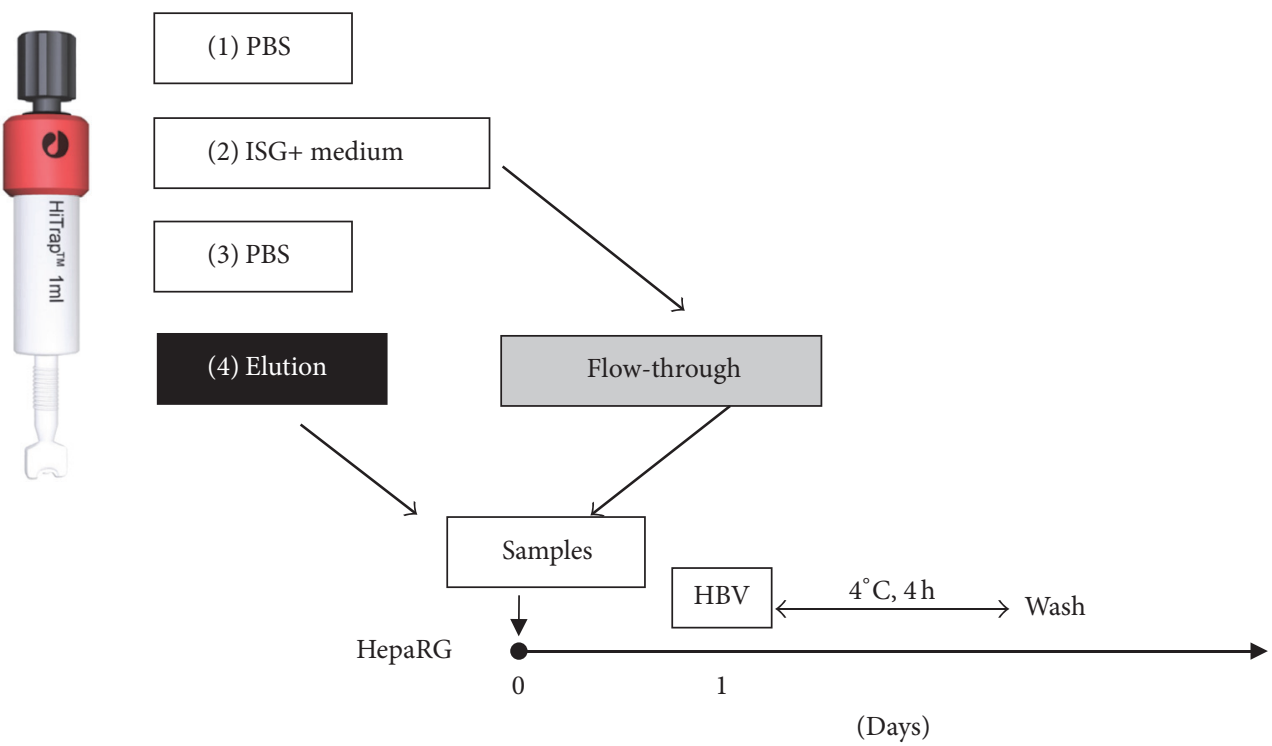

(a)



(b)

FIGURE 5: IFN- $\alpha$ induced products inhibit HBV binding to the cells. (a) Heparin columns were washed with PBS and then applied with IFN$\alpha$ treated differentiated HepaRG cell culture medium. Then columns were washed with PBS. Differentiated HepaRG cells were incubated with elution or flow-through for 24 hours followed by 4 hours of $\mathrm{HBV}$ incubation at $4^{\circ} \mathrm{C}$. (b) Cells were lysed and cellular HBV-DNA were evaluated by qPCR. Data are means \pm s.d. ${ }^{*} P<0.05,{ }^{* *} P<0.01$, and ${ }^{* * *} P<0.001$ by Student's unpaired two-tailed $t$-test.

3.5. Characterization of IFN- $\alpha$ Induced Binding Inhibitors. In order to characterize the active factors in ISG+ medium in more detail, we determined their size using size exclusion chromatography. The heparin binding fraction was purified and applied to size exclusion columns with a cut-off of $10 \mathrm{kDa}$, $30 \mathrm{kDa}$, and $100 \mathrm{kDa}$, respectively, to further concentrate and separate the fractions by protein size (Figure 6(a)). Both flow-through and concentrate from each column were collected, and six different fractions containing a different size range of proteins (Figure 6(b)) were incubated on differentiated HepaRG cells before HBV inoculation. Elution from heparin columns inhibited HBV replication as expected. Among different fractions, all three concentrates containing proteins bigger than $100 \mathrm{kDa}$ showed antiviral effects while all three flow-through fractions containing proteins smaller than $100 \mathrm{kDa}$ did not reduce infection (Figure 6(c)).

To confirm binding specificity of the IFN- $\alpha$ induced factors to heparin, we coated a plate with heparin and added the elution from heparin columns or different fractions from protein concentration columns. We then determined the amount of HBV that could still bind to the heparin plate (Figure 6(d)). The elution fraction or the respective concentrates from all size exclusion chromatography columns competed with HBV for binding to heparin. The three flow-through samples did not show any inhibition of HBV binding. Taken together, this suggested that the interferon induced secreted factors that inhibit binding of HBV to heparin are larger than $100 \mathrm{kDa}$. 

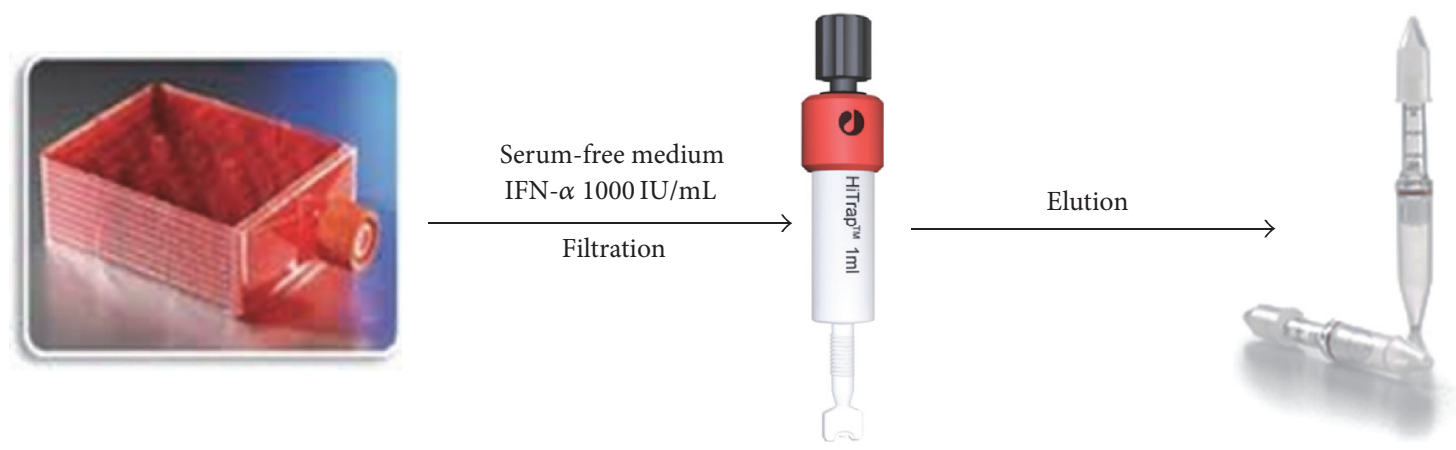

\begin{tabular}{lcc}
\hline Column & Flow-through & Concentrate \\
\hline $10 \mathrm{kDa}$ & $<10 \mathrm{kDa}$ & $\geq 10 \mathrm{kDa}$ \\
$30 \mathrm{kDa}$ & $<30 \mathrm{kDa}$ & $\geq 30 \mathrm{kDa}$ \\
$100 \mathrm{kDa}$ & $<100 \mathrm{kDa}$ & $\geq 100 \mathrm{kDa}$ \\
\hline
\end{tabular}

(b)



(d) (a)

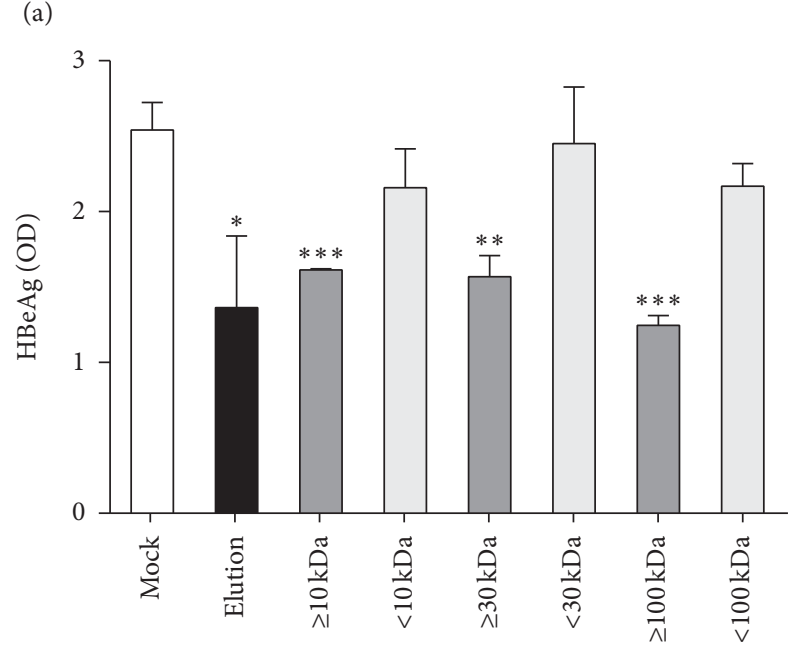

(c)

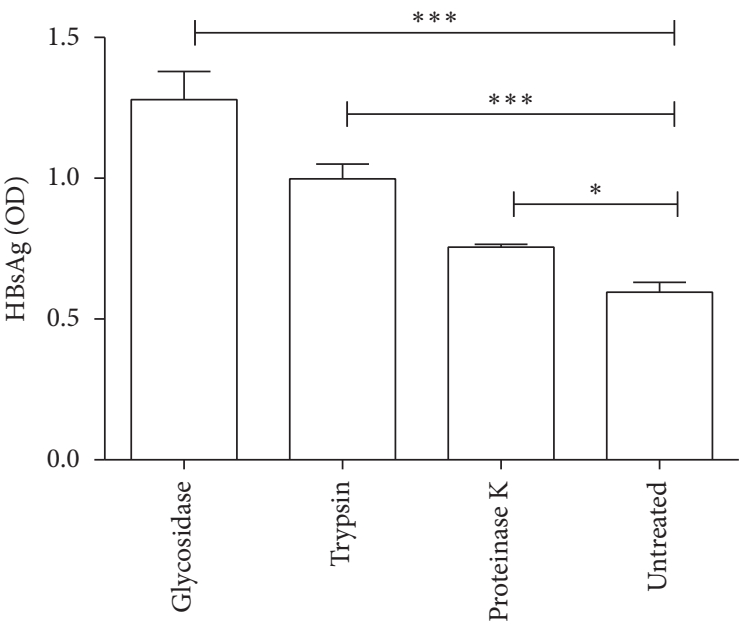

(e)

FIGURE 6: Size exclusion of IFN- $\alpha$ induced binding inhibitors. (a) HepaRG cells were cultivated in hyperflask. After differentiation, cells were stimulated with $1000 \mathrm{IU} / \mathrm{mL}$ IFN- $\alpha$ for one day and then fed fresh serum-free medium. The heparin binding fraction was purified from heparin columns and protein concentration columns with different cutoffs were used to further separate the fractions by protein size. (b) Protein size of each fraction. (c) Differentiated HepaRG cells were incubated with indicated samples for 24 hours and then infected with HBV. HBeAg was evaluated by ELISA 4 days after infection. (d) Highly purified HBV SVPs from chronic HBV carriers were added to heparin-coated $(25 \mu \mathrm{g} / \mathrm{mL})$ 96-well plate and treated with different fractions. Plates were incubated for $2 \mathrm{~h}$ at $37^{\circ} \mathrm{C}$, and heparin-bound SVPs were detected using an HBsAg ELISA kit. (e) Differentiated HepaRG cells were incubated with elution treated by glycosidase, or trypsin, or proteinase K for 24 hours and then infected with HBV. HBsAg was evaluated by ELISA 4 days after infection. 




FIGURE 7: IFN- $\alpha$ induced factors inhibit HCV replication. Huh7.5 cells were seeded in 96 -well plates in triplicate $24 \mathrm{~h}$ prior to virus infection. HCV luciferase reporter virus was used to infect cells at an MOI of 0.1 TCID50/cell. $1000 \mathrm{IU} / \mathrm{mL}$ of IFN- $\alpha, 10 \mu \mathrm{L}$ of prepared "elution" or "concentrate" was added to the culture medium (total volume $=200 \mu \mathrm{L}$ ) from the beginning of inoculation until the cells were lysed $72 \mathrm{~h}$ later after $\mathrm{HCV}$ infection. Luciferase activity was determined and one of two independent experiments is displayed as mean $\pm \mathrm{SD}$.

To further characterize the IFN- $\alpha$ induced binding inhibitors, we treated heparin column purified ISG+ medium (elution) with glycosidase, trypsin, or proteinase K (Figure 6(e)). Interestingly, all three enzyme treatments enhanced HBV replication, which indicated that the antiviral factors present in the ISG+ medium are glycoproteins. The strong inhibitory effect of glycosidase on the factors suggested that carbohydrate groups of the glycoproteins might play an important role in the interaction with heparan sulfate.

\subsection{Interferon Induced Secreted Factors Restrict HCV Infec-} tion. HCV is an alternative hepatotropic virus that uses heparan sulfate as a primary docking site for infection [26]. To investigate whether IFN-induced secreted factors were able to also inhibit HCV infection, IFN- $\alpha$ and heparin column elution or concentrate from $100 \mathrm{kDa}$ protein concentration columns were added during infection with HCV luciferase virus (Figure 7). Importantly, both elution fractions from heparin columns and concentrates from size exclusion columns also restricted HCV infection by $50 \%$ (Figure 7). This result confirms that IFN inducible secreted factors block HCV binding to heparin sulfate proteoglycans and thus are able to block this common step of the two hepatotropic viruses, $\mathrm{HBV}$ and $\mathrm{HCV}$.

\section{Discussion}

In the present study, we describe a novel antiviral mechanism of IFN- $\alpha$ that targets the HBV and HCV binding step. The supernatant of IFN- $\alpha$ treated cell cultures restricts HBV and HCV entry and infection. The inhibition is contributed by one or more secreted interferon induced proteins, which bind to heparin columns. This result indicates that the proteins in the IFN- $\alpha$ treated cell culture supernatant can bind to heparan glycosaminoglycans-the unspecific attachment receptor of many viruses.

Although ISG + medium was prepared from IFN- $\alpha$ treated cells, the antiviral activity of ISG+ medium was unlikely due to residual amount of IFN- $\alpha$ present in the conditioned medium or de novo synthesized IFN $-\alpha / \beta$ in ISG+ medium treated cells. First, the residual IFN- $\alpha$, if there was any, would be fast endocytosed and rapidly degraded by ISG producing cells [34]. Second, IFN- $\alpha$ treatment does not induce IFN- $\alpha / \beta$ production [35].

Initial interactions between an enveloped virus and its host cell are normally mediated through its membrane glycoproteins by binding to glycolipids and/or glycoprotein attachment factors, such as heparan sulfate proteoglycans, on the target cell surface [36]. For HBV, this first encounter is initiated via interaction of the "a" determinant(s) with heparan sulfate proteoglycans, resulting in the large envelope protein being able to bind to its specific receptor sodium-taurocholate cotransporting polypeptide to allow viral entry [25, 37]. Our enzyme digestion experiment suggested that IFN- $\alpha$ induced glycoproteins could compete with viral membrane proteins for binding to heparin sulfate proteoglycans thus blocking the whole entry process of virus infection.

IFN- $\alpha$ induced antiviral response is known to be multifunctional for a long time; however, its effects on the virus binding or entry steps are not well studied [38]. Until recently, the interferon-inducible transmembrane (IFITM) protein family has been shown to block early stages of viral infection $[39,40]$. IFITM was originally identified through RNAi genetic screening and was shown to inhibit infections of vesicular stomatitis virus (VSV), influenza A virus, West Nile virus, and Dengue virus. Later IFITM proteins were found to potently restrict entry and infections by a number of highly pathogenic viruses, including human immunodeficiency virus (HIV), filoviruses, HCV, and SARS coronavirus $[17,19,41-44]$. Recently, researchers identified cholesterol25-hydroxylase $(\mathrm{CH} 25 \mathrm{H})$ as a broad antiviral ISG [45]. $\mathrm{CH} 25 \mathrm{H}$ converts cholesterol into a soluble antiviral factor, 25-hydroxycholesterol (25HC). 25HC treatment in cultured cells inhibited growth of a broad group of enveloped viruses including VSV, HIV, and herpes simplex virus. Interestingly, it also blocks HBV entry [46]. Since the molecular weight of IFITM or $\mathrm{CH} 25 \mathrm{H}$ is less than $100 \mathrm{kDa}$, other factors that may contribute to the antiviral effect we observed.

The specific inhibition of virus entry is an attractive therapeutic target not only for acute but also for chronic viral infections. In the case of chronic infection entry inhibition prohibits infection from spreading to naive cells, which together with antiviral therapy eliminates infected cells providing higher chance of cure. For example, in HIV infection this has been accomplished with the interference of virus entry using a gp41 protein derived peptide, enfuvirtide, which prevents fusion of the virus with the host cellular membrane [47]. Virus entry inhibition also provides an opportunity to prevent recurrent hepatitis B after liver transplantation. Previous 
studies demonstrate that acylated HBV preS-derived lipopeptides targeting viral envelope protein components could prevent the interaction of $\mathrm{HBV}$ with its cellular receptor, thus preventing de novo HBV infection in humanized mice [48]. Since hepatitis Delta virus uses the same receptor as HBV, HBV entry inhibitors are equally effective against both viruses [49]. Although there is no evidence indicating that HBV can propagate by cell-to-cell transmission, numerous enveloped viruses have been shown to employ modes of spreading involving both direct cell-cell transmission and the release of progeny viruses into the extracellular space [50]. Further study showed the myristoylated preS-derived peptide Myrcludex-B could block HBV cell-to-cell dissemination among human hepatocytes in the liver of humanized mice [51]. Similarly, in the context of HCV infection, an entry inhibitor targeting viral receptor claudin-1 used in monotherapy was shown to cure chronic infection in the infected humanized mice [52].

Altogether, recent studies results indicate that inhibition of $\mathrm{HBV} / \mathrm{HCV}$ entry or binding, in combination with established therapies, might have potential applications in preventing vertical transmission during birth, reinfection after liver transplantation, or chronic $\mathrm{HBV}$ infection. In both $\mathrm{HBV}$ and HCV infection, hepatocyte turnover likely results in the reduced infection. Even more importantly, a recent clinical trial using entry inhibitor Myrcludex-B to treat patients with chronic hepatitis Delta has demonstrated that an entry inhibitor alone or in combination with IFN- $\alpha$ has a pronounced antiviral effect [53]. By blocking reinfection and protecting uninfected hepatocytes from de novo infection, IFN-induced viral entry inhibitors complement already known antiviral effects of IFN- $\alpha$ and their identification may open perspectives for novel therapeutic approaches for HBV and $\mathrm{HCV}$ infection.

\section{Conclusion}

In conclusion, this study reveals that IFN- $\alpha$ is able to induce soluble factors that bind to heparan glycosaminoglycans and lead to the inhibition of HBV and HCV binding and thus unravel a novel antiviral mechanism of action of interferons.

\section{Disclosure}

Current address of Yuchen Xia and Xiaoming Cheng is as follows: Liver Diseases Branch, National Institute of Diabetes and Digestive and Kidney Diseases (NIDDK), NIH, Bethesda, MD 20892, USA.

\section{Competing Interests}

The authors have no conflict of interests to disclose.

\section{Authors' Contributions}

Yuchen Xia and Ulrike Protzer designed the study; Yuchen Xia, Xiaoming Cheng, Christoph K. Blossey, and Knud Esser conducted research; Yuchen Xia, Xiaoming Cheng, and Ulrike Protzer analyzed data and wrote the manuscript; Karin
Wisskirchen revised the manuscript; all authors read and approved the manuscript.

\section{Acknowledgments}

This research was supported by the German Center for Infection Research (DZIF), the Helmholtz Validation Fond (HVF045), and the BMBF program KMU Innovative. Yuchen Xia is partly sponsored by The International Liver Cancer Association- (ILCA-) Fellowship. The authors would like to thank the NIH Fellows Editorial Board for reviewing the manuscript.

\section{References}

[1] A. Isaacs and J. Lindenmann, "Virus interference. I. The interferon," Proceedings of the Royal Society of London B, Biological sciences, vol. 147, no. 927, pp. 258-267, 1957.

[2] L. C. Platanias, "Mechanisms of type-I- and type-II-interferonmediated signalling," Nature Reviews Immunology, vol. 5, no. 5, pp. 375-386, 2005.

[3] J. Lucifora, Y. Xia, F. Reisinger et al., "Specific and nonhepatotoxic degradation of nuclear hepatitis B virus cccDNA," Science, vol. 343, no. 6176, pp. 1221-1228, 2014.

[4] Y. Xia, J. Lucifora, F. Reisinger, M. Heikenwalder, and U. Protzer, "Response to comment on "specific and nonhepatotoxic degradation of nuclear hepatitis B virus cccDNA"," Science, vol. 344, no. 6189, Article ID 1237, 2014.

[5] Y. Xia, D. Stadler, J. Lucifora et al., "Interferon- $\gamma$ and tumor necrosis factor- $\alpha$ produced by T cells reduce the HBV persistence form, cccDNA, without cytolysis," Gastroenterology, vol. 150, no. 1, pp. 194-205, 2016.

[6] F. Liu, M. Campagna, Y. Qi et al., "Alpha-interferon suppresses hepadnavirus transcription by altering epigenetic modification of cccDNA minichromosomes," PLoS Pathogens, vol. 9, no. 9, Article ID e1003613, 2013.

[7] L. Belloni, L. Allweiss, F. Guerrieri et al., "IFN- $\alpha$ inhibits HBV transcription and replication in cell culture and in humanized mice by targeting the epigenetic regulation of the nuclear cccDNA minichromosome," The Journal of Clinical Investigation, vol. 122, no. 2, pp. 529-537, 2012.

[8] S. L. Uprichard, S. F. Wieland, A. Althage, and F. V. Chisari, "Transcriptional and posttranscriptional control of hepatitis B virus gene expression," Proceedings of the National Academy of Sciences of the United States of America, vol. 100, no. 3, pp. 13101315, 2003.

[9] R. Mao, H. Nie, D. Cai et al., "Inhibition of hepatitis B virus replication by the host zinc finger antiviral protein," PLoS Pathogens, vol. 9, no. 7, Article ID e1003494, 2013.

[10] S. F. Wieland, A. Eustaquio, C. Whitten-Bauer, B. Boyd, and F. V. Chisari, "Interferon prevents formation of replicationcompetent hepatitis B virus RNA-containing nucleocapsids," Proceedings of the National Academy of Sciences of the United States of America, vol. 102, no. 28, pp. 9913-9917, 2005.

[11] N. Li, L. Zhang, L. Chen et al., "MxA inhibits hepatitis B virus replication by interaction with hepatitis B core antigen," Hepatology, vol. 56, no. 3, pp. 803-811, 2012.

[12] R. Yan, X. Zhao, D. Cai et al., “The interferon-inducible protein tetherin inhibits hepatitis B virus virion secretion," Journal of Virology, vol. 89, no. 18, pp. 9200-9212, 2015. 
[13] C. Xu, H. Guo, X.-B. Pan et al., "Interferons accelerate decay of replication-competent nucleocapsids of hepatitis B virus," Journal of Virology, vol. 84, no. 18, pp. 9332-9340, 2010.

[14] T. Saito, D. M. Owen, F. Jiang, J. Marcotrigiano, and M. Gale Jr., "Innate immunity induced by composition-dependent RIGI recognition of hepatitis C virus RNA," Nature, vol. 454, no. 7203, pp. 523-527, 2008.

[15] N. Arnaud, S. Dabo, D. Akazawa et al., "Hepatitis C virus reveals a novel early control in acute immune response," PLoS Pathogens, vol. 7, no. 10, Article ID e1002289, 2011.

[16] D. R. Taylor, M. Puig, M. E. R. Darnell, K. Mihalik, and S. M. Feinstone, "New antiviral pathway that mediates hepatitis $\mathrm{C}$ virus replicon interferon sensitivity through ADAR1," Journal of Virology, vol. 79, no. 10, pp. 6291-6298, 2005.

[17] D. Jiang, H. Guo, C. Xu et al., "Identification of three interferoninducible cellular enzymes that inhibit the replication of hepatitis C virus," Journal of Virology, vol. 82, no. 4, pp. 1665-1678, 2008.

[18] J.-Q. Han and D. J. Barton, "Activation and evasion of the antiviral 2/-5/ oligoadenylate synthetase/ribonuclease L pathway by hepatitis C virus mRNA," RNA, vol. 8, no. 4, pp. 512-525, 2002.

[19] C. Wilkins, J. Woodward, D. T.-Y. Lau et al., "IFITM1 is a tight junction protein that inhibits hepatitis C virus entry," Hepatology, vol. 57, no. 2, pp. 461-469, 2013.

[20] D. WuDunn and P. G. Spear, "Initial interaction of herpes simplex virus with cells is binding to heparan sulfate," Journal of Virology, vol. 63, no. 1, pp. 52-58, 1989.

[21] L. K. Hallak, P. L. Collins, W. Knudson, and M. E. Peeples, "Iduronic acid-containing glycosaminoglycans on target cells are required for efficient respiratory syncytial virus infection," Virology, vol. 271, no. 2, pp. 264-275, 2000.

[22] G. Roderiquez, T. Oravecz, M. Yanagishita, D. C. Bou-Habib, H. Mostowski, and M. A. Norcross, "Mediation of human immunodeficiency virus type 1 binding by interaction of cell surface heparan sulfate proteoglycans with the V3 region of envelope gp120-gp4," Journal of Virology, vol. 69, no. 4, pp. 22332239, 1995.

[23] T. Compton, D. M. Nowlin, and N. R. Cooper, "Initiation of human cytomegalovirus infection requires initial interaction with cell surface heparan sulfate," Virology, vol. 193, no. 2, pp. 834-841, 1993.

[24] Y. Chen, T. Maguire, R. E. Hileman et al., "Dengue virus infectivity depends on envelope protein binding to target cell heparan sulfate," Nature Medicine, vol. 3, no. 8, pp. 866-871, 1997.

[25] A. Schulze, P. Gripon, and S. Urban, "Hepatitis B virus infection initiates with a large surface protein-dependent binding to heparan sulfate proteoglycans," Hepatology, vol. 46, no. 6, pp. 1759-1768, 2007.

[26] H. Barth, C. Schäfer, M. I. Adah et al., "Cellular binding of hepatitis $\mathrm{C}$ virus envelope glycoprotein $\mathrm{E} 2$ requires cell surface heparan sulfate," Journal of Biological Chemistry, vol. 278, no. 42, pp. 41003-41012, 2003.

[27] T. Giroglou, L. Florin, F. Schäfer, R. E. Streeck, and M. Sapp, "Human papillomavirus infection requires cell surface heparan sulfate," Journal of Virology, vol. 75, no. 3, pp. 1565-1570, 2001.

[28] D. Sa-Carvalho, E. Rieder, B. Baxt, R. Rodarte, A. Tanuri, and P. W. Mason, "Tissue culture adaptation of foot-and-mouth disease virus selects viruses that bind to heparin and are attenuated in cattle," Journal of Virology, vol. 71, no. 7, pp. 5115$5123,1997$.
[29] J. Lucifora, S. Arzberger, D. Durantel et al., "Hepatitis B virus $\mathrm{X}$ protein is essential to initiate and maintain virus replication after infection," Journal of Hepatology, vol. 55, no. 5, pp. 996$1003,2011$.

[30] G. Koutsoudakis, A. Kaul, E. Steinmann et al., "Characterization of the early steps of hepatitis $\mathrm{C}$ virus infection by using luciferase reporter viruses," Journal of Virology, vol. 80, no. 11, pp. 5308-5320, 2006.

[31] T. Pietschmann, A. Kaul, G. Koutsoudakis et al., "Construction and characterization of infectious intragenotypic and intergenotypic hepatitis C virus chimeras," Proceedings of the National Academy of Sciences of the United States of America, vol. 103, no. 19, pp. 7408-7413, 2006.

[32] M. Krepstakies, J. Lucifora, C.-H. Nagel et al., "A new class of synthetic peptide inhibitors blocks attachment and entry of human pathogenic viruses," The Journal of Infectious Diseases, vol. 205, no. 11, pp. 1654-1664, 2012.

[33] A. Zahn and J. P. Allain, "Hepatitis $C$ virus and hepatitis B virus bind to heparin: purification of largely IgG-free virions from infected plasma by heparin chromatography," Journal of General Virology, vol. 86, no. 3, pp. 677-685, 2005.

[34] K. C. Zoon, H. Arnheiter, D. Z. Nedden, D. J. P. Fitzgerald, and M. C. Willingham, "Human interferon alpha enters cells by receptor-mediated endocytosis," Virology, vol. 130, no. 1, pp. 195-203, 1983.

[35] S. D. Der, A. Zhou, B. R. G. Williams, and R. H. Silverman, "Identification of genes differentially regulated by interferon $\alpha$, $\beta$, or $\gamma$ using oligonucleotide arrays," Proceedings of the National Academy of Sciences of the United States of America, vol. 95, no. 26, pp. 15623-15628, 1998.

[36] M. Marsh and A. Helenius, "Virus entry: open sesame," Cell, vol. 124, no. 4, pp. 729-740, 2006.

[37] H. Yan, G. Zhong, G. Xu et al., "Sodium taurocholate cotransporting polypeptide is a functional receptor for human hepatitis B and D virus," eLife, vol. 1, Article ID e00049, 2012.

[38] Y. Xia and U. Protzer, "Control of hepatitis B virus by cytokines," Viruses, vol. 9, article 18, 2017.

[39] F. Siegrist, M. Ebeling, and U. Certa, "The small interferoninduced transmembrane genes and proteins," Journal of Interferon and Cytokine Research, vol. 31, no. 1, pp. 183-197, 2011.

[40] A. L. Brass, I.-C. Huang, Y. Benita et al., "The IFITM proteins mediate cellular resistance to influenza A H1N1 virus, West Nile virus, and dengue virus," Cell, vol. 139, no. 7, pp. 1243-1254, 2009.

[41] I.-C. Huang, C. C. Bailey, J. L. Weyer et al., "Distinct patterns of IFITM-mediated restriction of filoviruses, SARS coronavirus, and influenza A virus," PLoS Pathogens, vol. 7, no. 1, Article ID e1001258, 2011.

[42] J. M. Weidner, D. Jiang, X.-B. Pan, J. Chang, T. M. Block, and J.T. Guo, "Interferon-induced cell membrane proteins, IFITM3 and tetherin, inhibit vesicular stomatitis virus infection via distinct mechanisms," Journal of Virology, vol. 84, no. 24, pp. 12646-12657, 2010.

[43] J. Lu, Q. Pan, L. Rong, S.-L. Liu, and C. Liang, "The IFITM proteins inhibit HIV-1 infection," Journal of Virology, vol. 85, no. 5, pp. 2126-2137, 2011.

[44] Y. K. Chan, I.-C. Huang, and M. Farzan, "IFITM proteins restrict antibody-dependent enhancement of dengue virus infection," PLoS ONE, vol. 7, no. 3, Article ID e34508, 2012.

[45] S.-Y. Liu, R. Aliyari, K. Chikere et al., "Interferon-inducible cholesterol-25-hydroxylase broadly inhibits viral entry by production of 25-hydroxycholesterol," Immunity, vol. 38, no. 1, pp. 92-105, 2013. 
[46] M. Iwamoto, K. Watashi, S. Tsukuda et al., "Evaluation and identification of hepatitis B virus entry inhibitors using HepG2 cells overexpressing a membrane transporter NTCP," Biochemical and Biophysical Research Communications, vol. 443, no. 3, pp. 808-813, 2014.

[47] J. M. Kilby, S. Hopkins, T. M. Venetta et al., "Potent suppression of HIV-1 replication in humans by T-20, a peptide inhibitor of gp41-mediated virus entry," Nature Medicine, vol. 4, no. 11, pp. 1302-1307, 1998.

[48] J. Petersen, M. Dandri, W. Mier et al., "Prevention of hepatitis $B$ virus infection in vivo by entry inhibitors derived from the large envelope protein," Nature Biotechnology, vol. 26, no. 3, pp. 335-341, 2008.

[49] W. Li and S. Urban, "Entry of hepatitis B and hepatitis D virus into hepatocytes: basic insights and clinical implications," Journal of Hepatology, vol. 64, no. 1, pp. S32-S40, 2016.

[50] Q. J. Sattentau, "The direct passage of animal viruses between cells," Current Opinion in Virology, vol. 1, no. 5, pp. 396-402, 2011.

[51] T. Volz, L. Allweiss, M. B. MBarek et al., "The entry inhibitor Myrcludex-B efficiently blocks intrahepatic virus spreading in humanized mice previously infected with hepatitis B virus," Journal of Hepatology, vol. 58, no. 5, pp. 861-867, 2013.

[52] L. Mailly, F. Xiao, J. Lupberger et al., "Clearance of persistent hepatitis $\mathrm{C}$ virus infection in humanized mice using a claudin1-targeting monoclonal antibody," Nature Biotechnology, vol. 33, no. 5, pp. 549-554, 2015.

[53] P. Bogomolov, A. Alexandrov, N. Voronkova et al., "Treatment of chronic hepatitis D with the entry inhibitor myrcludex B: First results of a phase Ib/IIa study," Journal of Hepatology, vol. 65, no. 3, pp. 490-498, 2016. 


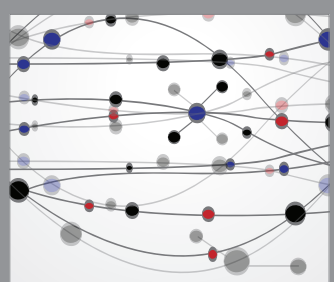

The Scientific World Journal




Gastroenterology Research and Practice
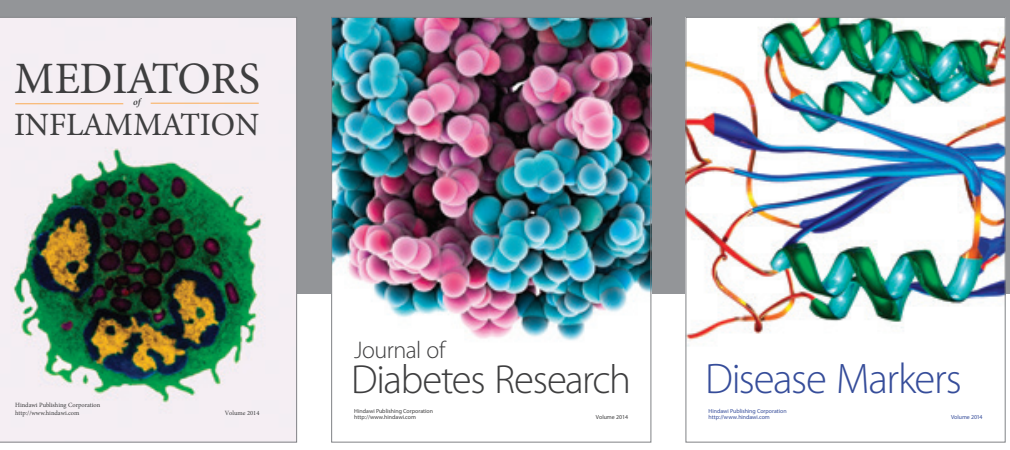

Disease Markers

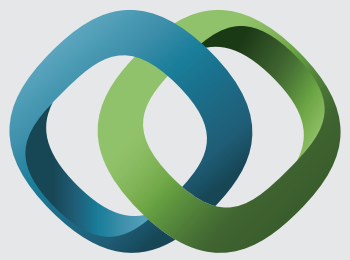

\section{Hindawi}

Submit your manuscripts at

https://www.hindawi.com
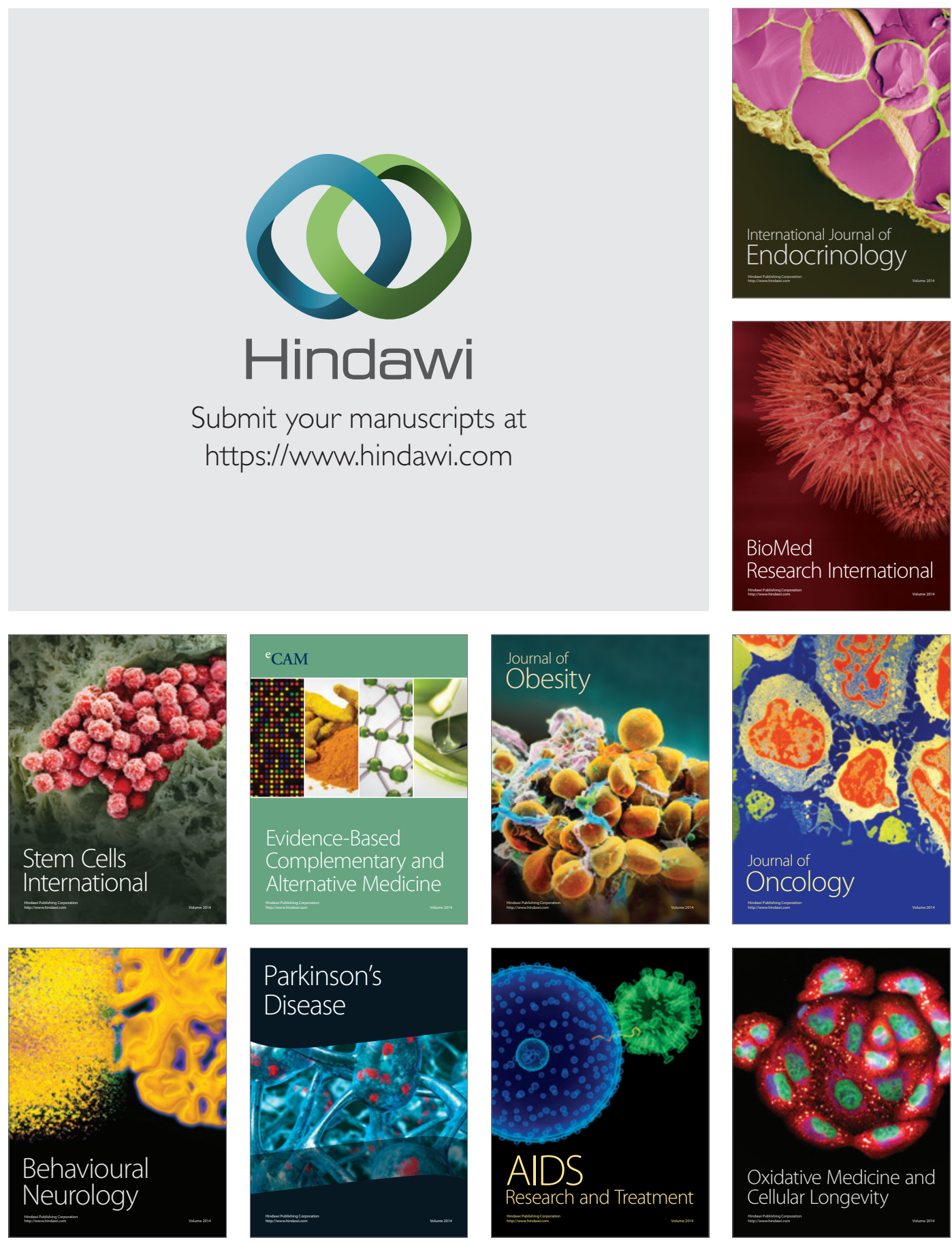